\title{
Implementasi Algoritma Jean Meeus dalam Penentuan Waktu Shalat Sunnah Tertentu Berbasis Android
}

\author{
M. Bayu Wibisono, Ahmad Fauzi, Indra Permana Solihin \\ Teknik Informatika \\ Fakultas Ilmu Komputer \\ Universitas Pembangunan Nasional "Veteran" Jakarta \\ Jalan Rs Fatmawati, Pondok Labu, Jakarta Selatan Telp./Fax.021-7669069 \\ masbayu.ok@gmail.com, ahmadfauzi@gmail.com, Indrapermana@upnvj.ac.id,
}

\begin{abstract}
Abstrak - Era teknologi informasi saat ini, peran informasi sangat penting dalam menjawab setiap kebutuhan. Waktu merupakan sesuatu yang berharga bagi kehidupan manusia. Semua aktivitas manusia tidak akan luput dari konteks waktu, untuk meningkatkan iman kita kepada Tuhan YME, tidak cukup hanya dengan melakukan kewajiban, tetapi juga membutuhkan ekstra intensitas untuk meningkatkan iman. Doa sunnah adalah doa yang sangat dianjurkan untuk dilaksanakan tetapi sangat disayangkan ketika ditinggalkan, dalam shalat sunah ada waktu yang sangat tepat untuk melakukannya. Untuk dapat menentukan waktu yang tepat. banyak metode dan pendapat yang berbeda, dalam penggunaan algoritma waktu doa, salah satunya adalah algoritma JEAN MEEUS diturunkan dari algoritma VSOP87 yang memiliki tingkat akurasi yang tinggi. Dari ribuan algoritma, menggunakan suku VSOP87 dapat mengoreksi dan ketelitian dalam menentukan posisi matahari, maka yang terpenting adalah tentang ratusan suku yang besar dalam algoritma jean meeus, sedangkan rumpun kecil tidak diperhitungkan, tetapi tidak mengurangi tingkat akurasi algoritma. Smartphone berbasis Android adalah salah satu alat yang dapat digunakan untuk menyampaikan informasi. Aplikasi ini dirancang menggunakan program berbasis android untuk menghasilkan aplikasi jadwal yang tepat untuk melakukan shalat sunnah.
\end{abstract}

Kata Kunci: Waktu, Shalat Sunnah, Jean Meeus Algorithm, VSOP87 Algorithm, Android.

\section{PENDAHULUAN}

Perkembangan Teknologi Informasi memacu suatu cara baru dalam kehidupan, dimulai dari cara penentuan waktu dalam menyusun agenda pekerjaan, pendidikan, kesehatan, maupun membantu dalam menentuan waktu shalat.

Shalat sunnah atau shalat nawafil adalah shalat yang sangat dianjurkan untuk dilaksanakan namun sangat disayangkan apabila ditinggalkan, dengan kata lain apabila dilakukan dengan baik dan benar serta penuh keiklasan, akan tampak hikmah dan rahmat dari ALLAH SWT.

Dalam HR. Muslim menjelaskan tentang sabda Rasulullah shalallahu'alaihi wa sallam "barang siapa yang shalat dua belas rakaat pada siang dan malam, maka akan dibangunkan baginya rumah di surga".

Algoritma Jean Meeus adalah reduksi dari algoritma VSOP87 yang memiliki tingkat akurasi tinggi, dari ribuan suku koreksi dari algoritma VSOP87 untuk menentukan posisi matahari, maka yang diperhitungkan adalah sekitar ratusan suku-suku yang besar dan penting pada Algoritma Jean Meeus ini, suku-suku yang kecil tidak perlu diperhitungkan lagi.

Maka berdasarkan uraian diatas dalam menentukan jadwal yang tepat untuk melakukan shalat sunnah yang tepat dan menurut anjuran dari berbagai hadist yang sesuai, Metode equation of time versi Algoritma Jean Meeus ini merupakan metode yang tepat, mudah, dan efektif untuk menentukan waktu yang paling baik melaksanakan shalat sunnah.

Shalat sunnah yang akan dihitung waktu pelaksanaan paling baik menurut hadist adalah shalat sunnah dhuha dan shalat sunnah tahajud, tidak mencakup perhitungan shalat sunnah yang lain tapi tidak menutup kemungkinan untuk menjelaskan tentang shalat sunnah lain. 


\section{Studi Literatur}

Beberapa hasil penelitian terdahulu yang dibuat sebelumnya sebagai bahan referensi dalam penelitian ini antara lain:

a) Hasil penelitian menurut Reza Akbar (2017) yang berjudul "Perhitungan Data Empiris Koordinat Matahari Menggunakan Algoritma Jean Meeus Higher Accuracy dan Keterkaitannya Dengan Pengembangan Ilmu Falak ", menunjukkan bahwa penggunaan algoritma dan proses perhitungan data ephemeris agar dihasilkan data yang benar-benar akurat dan lebih baik, serta kepastian hasilnya dalam menentukan perhitungan data. Persamaan penelitian diatas dengan penelitian penulis yaitu, menggunakan algoritma sebagai penghasil data yang akurat dalam menentukan, dimana Reza Akbar untuk menghasilkan data akurat sedangkan peneliti untuk mendapatkan hasil yang akurat melalui algoritma meeus dalam penentuan waktu shalat. Penelitian Reza Akbar perhitungan data untuk koordinat matahari sedangkan peneliti menggunakan algoritma meeus untuk penentuan letak matahari jadwal waktu shalat.

b) Hasil penelitian menurut Dede Muhammad Isnaeni, Fitri Mintarsih, dan Feri Fahrianto (2015) yang berjudul “Implementasi Algoritma Jean Meeus Dalam Penentuan Waktu Shalat Dan Pencarian Masjid Terdekat ", menunjukkan bahwa dengan memanfaatkan teknologi yang ada pada Smartphone khususnya yang berbasis sistem operasi Android, pengguna bisa dengan cepat mengetahui waktu shalat dan lokasi masjid yang berada paling dekat dengan posisi dia berada menggunakan sebuah aplikasi yang dirancang untuk dapat mengetahui waktu shalat dan masjid terdekat. Persamaan penelitian diatas dengan penelitian penulis yaitu, menerapkan implementasi Algoritma Jean Meeus dalam penetuan waktu shalat yang menggunakan aplikasi berbasis Android. Penelitian Dede Muhammad Isnaeni, Fitri Mintarsih, dan Feri Fahrianto mengimplementasikan algoritma meeus dalam penentuan shalat sama dengan peneliti untuk menghitung dan menentukan waktu shalat menggunakan implementasi Algoritma Jean Meeus.

c) Hasil Penelitian menurut Arif Agus P, Sugeng Rianto, dan Abdurrouf (2012) yang berjudul " Pembuatan Aplikasi untuk Menentukan Fase dan Visibilitas Bulan dengan Menggunakan Algoritma Jean Meeus “, menunjukkan bahwa Aplikasi yang telah dibuat dapat berjalan lebih baik dengan indikasi output aplikasi sama dengan output aplikasi lain dan data pembanding, dimana probabilitas kenampakan bulan pada suatu lokasi sangat bergantung pada letak geografis lokasi pengamatan, kapan waktu dilakukannya pengamatan dan posisi bulan saat itu (bedasarkan koordinat ekliptika geosentrik, ekuator dan horison). Terutama posisi bulan pada koordinat horison (altitude dan azimuth) karena pusat acuan berdasarkan posisi pengamat. Persamaan penelitian diatas dengan penelitian penulis yaitu, pembuatan aplikasi dengan menggunakan Algoritma Jean Meeus tetapi penerapannya di penelitian kepada bulan sedangkan penulis menerapkan untuk letak matahari sebagai arah penentuan waktu shalat sunnah. Penelitian Arif Agus P, Sugeng Rianto, dan Abdurrouf penerapan algoritma pada posisi bulan sedangkan peneliti penggunaan untuk letak matahari sebagai arah penentuan shalat.

d) Hasil penelitian menurut Tolha Hasyim Fanani (2011) yang berjudul "Metode Pengumpulan Waktu Shalat Di Masjid - Masjid Kabupaten Malang “, menunjukkan bahwa metode perhitungan matahari (jam matahari) dan bencret (bencet) untuk menentukan awal waktu shalat lebih baik dibandingkan dengan menggunakan metode yang menggunakan informasi setempat yang didapatkan melalui radio ataupun informasi lainnya. Persamaan penelitian di atas dengan penelitian penulis yaitu, menerapkan metode perhitungan matahari (jam matahari) melalui perbedaan posisi lingkar dan bujur waktu letak matahari. Perbedaan penelitian di atas membandingkan penerapan metode perhitungan matahari (jam matahari) dengan metode manual yang mengikuti informasi daerah setempat. Penelitian Tolha Hasyim Fanani mengukur waktu pengumpulan sama dengan peneliti menghitung waktu solat menggunakan metode jam matahari.

\section{PEMBAHASAN}

Diagram alur ini menunjukan gambaran kerangka penelitian yang dilakukan tahap demi tahap sebagai pedoman dalam penelitian agar hasil yang dicapai tidak menyimpang dari tujuan sehingga mendapatkan hasil yang relevan. Tahap-tahap yang akan dilalui dalam metode penelitian dapat dilihat pada Gambar 1. 


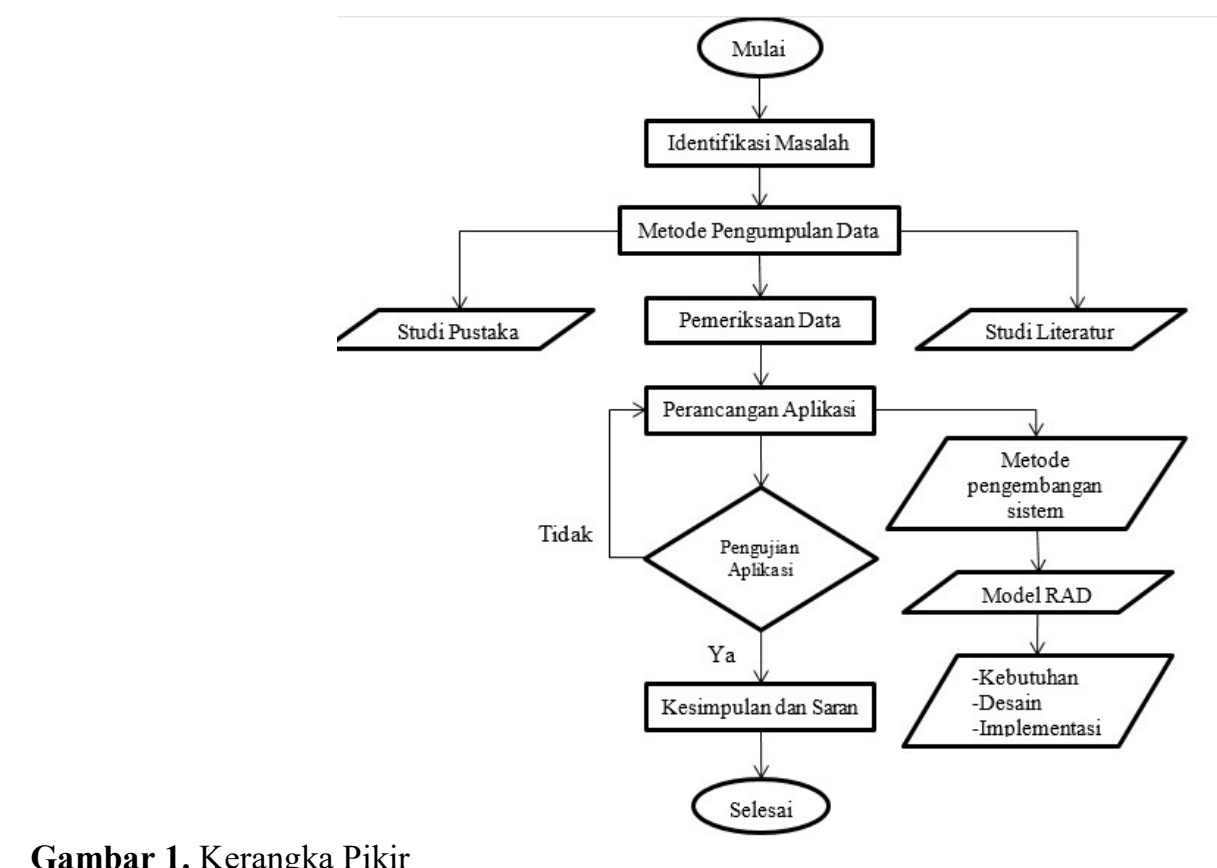

Gambar 1. Kerangka Pikir

- Data Penelitian

Menurut jurnal yang ditulis isnaeni, mintarsih, dan fahrianto serta pada buku mekanika benda langit karya Dr. Eng. Rinto Anugraha, M. Si. untuk menentukan waktu terbenam matahari menggunakan algoritma jean meeus cukup menggunakan metode equation of time dan mempunyai input zona waktu, lintang bujur, dan hari. Setelah itu dapat di hitung menggunakan rumus yang bertujuan menghitung julian day, julian day local dan equation of time. Kemudia didapat waktu terbenam matahari berupa bilangan variable yang dapat diconvert menjadi sebuah jam.

- $\quad$ Metode Pengembangan Sistem

Dalam pengembangkan aplikasi ini penelitian menggunakan pendekatan metode pengembangan sistem Rapid Application Development (RAD) menurut teori kendall dan Kendall. Sedangkan tools yang digunakan adalah notasi unified modelling berorientasi objek menurut jetfery L. Whitten adalah suatu pendekatan berorientasi objek terhadap pengembangan sistem yang mencakup suatu metode pengembangan sistem perangkatperangkat lunak. Pengembangan sistem RAD memiliki tiga fase yakni penilaian, perancangan, dan penerapan yang melibatkan penganalisis dan penggunaan. Gambar dibawah ini menggambarkan ketiga fase ini.

Sumber: Rekayasa Perangkat Lunak, 2016

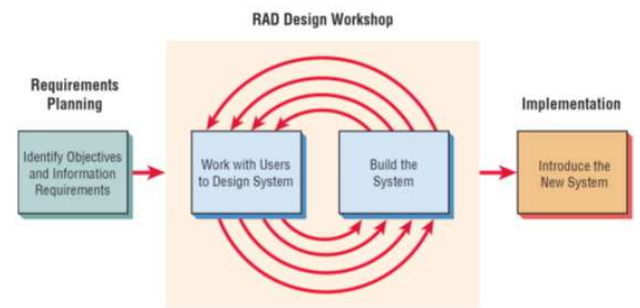

Gambar 2. Fase Rapid Application Development

- Fase Perancangan Kebutuhan

Pada fase ini, penulis mengidentifikasikan tujuan-tujuan aplikasi atau sistem untuk mengidentifikasi kebutuhan-kebutuhan data serta sistem yang dibutuhkan untuk membangun aplikasi tersebut. 
Pada fase perancangan kebutuhan, yang dilakukan antara lain:

a) Melakukan studi pada literatur yang membahas tentang waktu shalat, shalat sunnah dan tentang algoritma jean meeus.

b) Menganalisa sistem yang akan dibangun.

c) Melakukan identifikasi masalah yang tejadi.

- $\quad$ Fase Workshop Desain RAD

Fase ini adalah fase untuk merancang sistem yang akan dibuat atau bisa juga untuk memperbaiki sistem yang sudah dibuat. Adapun fase ini terdiri dari dua hal, yaitu design sistem dan build sistem.

Fase ini dicirikan dengan workshop karena layaknya sebuah workshop yang terdapat para partisipan yang berpartisipasi kuat dalam kelompok. Partisipan tersebut dianalogikan sebagai kelompok-kelompok kecil (group decision support system) yang dibentuk untuk membantu pengguna dalam menyetujui desain.

- $\quad$ Fase Implementasi

Setelah aplikasi selesai dibangun, dilakukan implementasi kepada pengguna untuk memperoleh hasil yang diharapkan, maka dilakukan uji coba atau system testing.

Pada tahap ini jika sistem dikembangkan belum sesuai dengan yang diharapkan, maka peneliti melakukan revisi terhadap aplikasi. Pada penelitian ini dilakukan pengujian aplikasi dengan metode emulator secara mandiri.

- Alat Bantu Analisis dan Perancangan

Dalam analisis dan perancangan penyusun menggambarkan bagaimana karakteristik sistem dengan menggunakan pemodelan yang disebut Unifield Modelling Language (UML).

Unified Modelling Language (UML) adalah bahasa pemodelan secara grafis untuk menspesifikasikan, memvisualisasikan, membangun, dan mendokumentasikan seluruh rancangan sistem perangkat lunak. Penggunaan model ini bertujuan untuk mengidentifikasikan bagian-bagian yang termasuk dalam lingkup sistem yang dibahas dan bagaimana hubungan antara sistem dengan subsistem maupun sistem lain di luarnya. Selain itu UML adalah bahasa pemodelan yang menggunakan konsep orientasi objek. UML dibuat oleh Grady Booch, James Rumbaugh, dan Ivar Jacobson di bawah bendera Rational Software Corp. UML menyediakan notasi-notasi yang membantu memodelkan sistem dari berbagai perspektif. UML tidak hanya digunakan dalam pemodelan perangkat lunak, namun hampir dalam semua bidang yang membutuhkan pemodelan.

Berikut ini definisi Unified Modeling Language (UML) menurut para ahli:

a) Unified Modeling Language (UML) adalah alat bantu analisis serta perancangan perangkat lunak berbasis objek (Nugroho, 2009).

b) Unified Modeling Language (UML) merupakan standard modeling language yang terdiri dari kumpulankumpulan diagram, dikembangkan untuk membantu para pengembang sistem dan software agar bisa menyelesaikan tugas-tugas seperti: Spesifikasi, Visualisasi, Desain Arsitektur, Konstruksi, Simulasi dan testing serta Dokumentasi (Soetra, 2007).

Berdasarkan beberapa pendapat yang dikemukakan diatas dapat ditarik kesimpulan bahwa "Unified Modeling Language (UML) adalah sebuah bahasa yang berdasarkan grafik atau gambar untuk menvisualisasikan, menspesifikasikan, membangun dan pendokumentasian dari sebuah sistem pengembangan perangkat lunak berbasis OO (Object Oriented)".

Unified Modelling Language (UML) adalah sebuah bahasa untuk menentukan, visualisasi, konstruksi, dan mendokumentasikan artifacts dari sistem software, untuk memodelkan bisnis, dan sistem nonsoftware lainnya. Artifacts adalah sepotong informasi yang digunakan atau dihasilkan dalam suatu proses rekayasa software. Artifacts dapat berupa model, deskripsi, atau software. Untuk membuat suatu model, UML memiliki diagram grafis yang diberi nama berdasarkan sudut pandang yang berbeda-beda terhadap sistem dalam proses analisa atau rekayasa. 
- Use Case Diagram

Use Case Diagram adalah suatu kumpulan urutan interaksi di antara user dengan sistem untuk mencapai suatu tujuan di mana use case ini menggambarkan kebutuhan fungsional suatu sistem tanpa menampilkan struktur internal sistem.

- Activity Diagram

Activity diagram adalah representasi secara grafis dari proses dari proses dan control flow dan berfungsi untuk memperlihatkan alur dari satu aktivitas ke aktivitas yang lain serta menggambarkan perilaku yang kompleks.

- Sequence Diagram

Sequence diagram adalah suatu diagram yang menggambarkan interaksi antar objek dan mengindikasikan komunikasi diantara objek-objek tersebut. Diagram ini juga menunjukkan serangkaian pesan yang dipertukarkan oleh objek-objek yang melakukan suatu tugas atau aksi tertentu. Objek-objek tersebut kemudian diurutkan dari kiri ke kanan, aktor yang menginisiasi interaksi biasanya ditaruh di paling kiri dari diagram.

- Class Diagram

Diagram kelas atau class diagram menggambarkan struktur sistem dari segi pendefinisian kelas - kelas yang akan dibuat untuk membangun sistem. Kelas memiliki apa yang disebut atribut dan metode atau operasi. Atribut merupakan variabel - variabel yang dimiliki oleh suatu kelas sedangkan operasi atau metode adalah fungsi - fungsi yang dimiliki oleh suatu kelas.

- Component Diagram

Component diagram adalah diagram yang menunjukkan organisasi dan kebergantungan di antara sekumpulan komponen. Diagram ini memodelkan pandangan implementasi fisik dari sistem.

- Deployment Diagram

Deployment diagram adalah penggambaran tugas-tugas kongkrit dari setiap node/software yang terlibat dalam jaringan sistem, menampilkan keseluruhan node dalam jaringan serta hubungan dari node-node tersebut termasuk proses-proses yang terlibat di dalamnya.

- Pengujian Software

Pengujian dilakukan untuk mendapatkan suatu perangkat lunak yang 'layak' untuk digunakan. Suatu perangkat lunak yang telah selesai diujikan harus memiliki standard kualitas tertentu.

Black box testing adalah metode pengujian perangkat lunak yang tes fungsionalitas dari aplikasi yang bertentangan dengan struktur internal atau kerja. Pengetahuan khusus dari kode aplikasi / struktur internal dan pengetahuan pemrograman pada umumnya tidak diperlukan. Uji kasus dibangun di sekitar spesifikasi dan persyaratan, yakni, aplikasi apa yang seharusnya dilakukan. Menggunakan deskripsi eksternal perangkat lunak termasuk spesifikasi, persyaratan, dan desain untuk menurunkan uji kasus. Ini dapat menjadi fungsional atau non-fungsional, meskipun biasanya fungsional. Perancang uji memilih input yang valid dan tidak valid dan menentukan output yang benar. Tidak ada pengetahuan tentang struktur internal benda uji itu.

Metode uji dapat diterapkan pada semua tingkat pengujian perangkat lunak: unit, integrasi, fungsional, sistem dan penerimaan. Ini biasanya terdiri dari kebanyakan jika tidak semua pengujian pada tingkat yang lebih tinggi, tetapi juga bisa mendominasi unit testing juga.

- Objek Penelitian

Objek yang ditargetkan pada penelitian ini adalah waktu terbaik untuk melakukan shalat sunnah dhuha dan shalat sunnah tahajud dengan menggunakan perangkat android. 


\section{HASIL}

Perancangan adalah suatu bagian dari metodologi pengembangan pembangunan suatu perangkat lunak yang digunakan setelah tahapan untuk memberikan gambaran secara terperinci.

Berdasarkan uraian diatas perancangan sistem merupakan tahapan dari siklus pengembangan sistem yang didefinisikan dari kebutuhan-kebutuhan fungsional dan persiapan untuk rancang bangun implementasi yang menggambarkan bagaimana suatu sistem dibentuk, yang dapat berupa penggambaran, perancangan, dan pembuatan sketsa atau pengaturan dari beberapa elemen yang terpisah kedalam satu kesatuan yang utuh dan berfungsi, juga menyangkut konfigurasi dari komponen - komponen perangkat keras dan perangkat lunak dari suatu sistem.

\section{Dse Case Diagram}

Usecase Diagram merupakan suatu aktivitas yang menggambarkan urutan interaksi antara satu atau lebih aktor dan sistem. Usecase yang akan dirancang yaitu usecase diagram untuk pengaksesan melalui perangkat android.

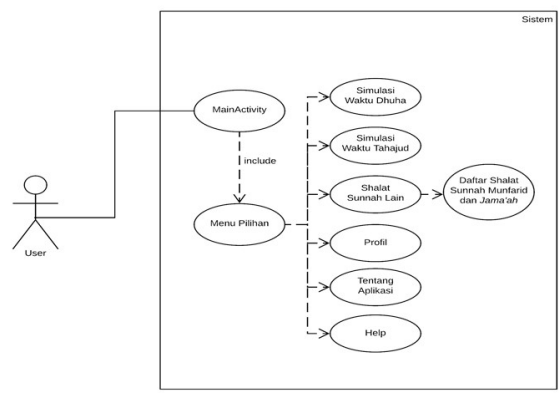

Gambar 3. Use Case Diagram

\section{Activity Diagram}

Activity diagram merupakan alur kerja pada setiap usecase. Dalam sistem, User dapat masuk kedalam sistem dan dapat melihat semua tampilan menu

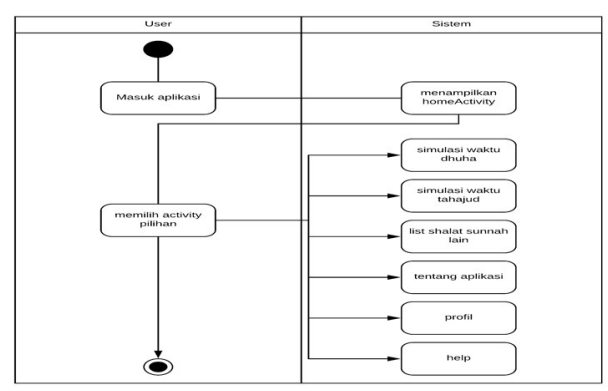

Gambar 4. Activity Diagram

\section{$>$ Sequence Diagram}

Sequence diagram merupakan interaksi antara objek-objek dalam suatu sistem dan terjadi komunikasi yang berupa tampilan serta parameter waktu. Dimulai dari user masuk ke aplikasi lalu sistem akan menampilkan splashscreen setelah itu sistem akan menampilkan homeactivity atau menu tampilan. Jika user masuk kedalam menu sunnah lain sistem akan mengambil data dari server lalu ditampilkan kepada user 


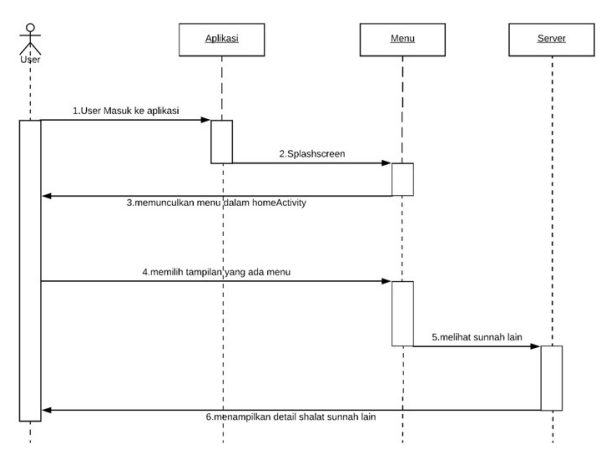

Gambar 5. Sequence Diagram

\section{Class Diagram}

Class diagram menggambarkan struktur dan deskripsi class, package, dan objek yang saling terhubung. Class diagram yang dibutuhkan dalam perancangan aplikasi shalat sunnah tahajud dan dhuha dengan simulasi.

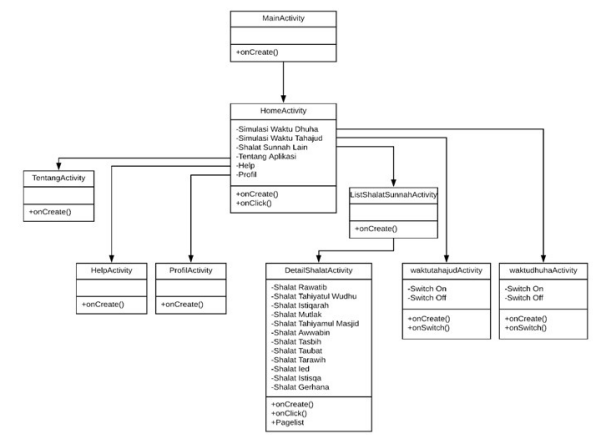

Gambar 6. Class Diagram

\section{$>$ Component Diagram}

Component diagram menggambarkan struktur dan hubungan antar komponen piranti lunak, umumnya komponen terbentuk dari beberapa class atau package, tapi dapat juga dari komponen - komponen yang lebih kecil. Komponen dapat juga berupa interface, yaitu kumpulan layanan yang disediakan sebuah komponen untuk komponen lain.

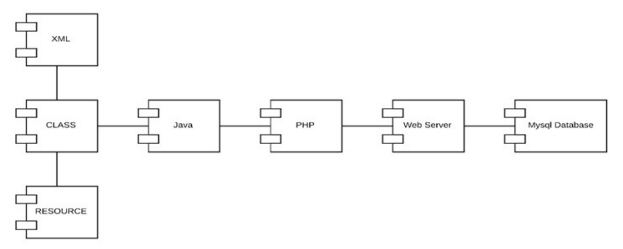

Gambar 7. Component Diagram

\section{$>$ Deployment Diagram}

Deployment diagram menggambarkan detail bagaimana komponen di-deploy dalam infrastuktur sistem, di mana komponen akan terletak (pada mesin, server atau piranti keras lain), bagaimana kemampuan jaringan pada lokasi tersebut, spesifikasi server, dan hal-hal lain yang bersifat fisik. Sebuah node adalah server, workstation, atau piranti keras lain yang digunakan untuk men-deploy komponen dalam lingkungan sebenarnya. 


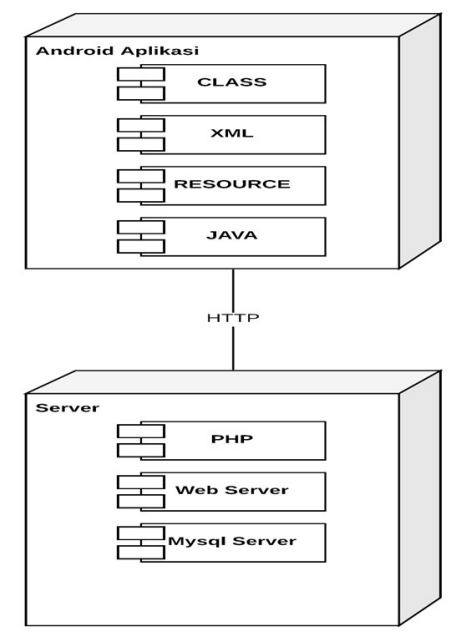

Gambar 8.Deployment Diagram

\section{A. Implementasi Algoritma}

Implementasi Algoritma diambil berdasarkan Algoritma jean meeus, secara garis besar algoritma jean meeus memiliki banyak metode untuk mencari dan menghitung pergerakan bumi, matahari, bulan maupun benda langit lain. Untuk aplikasi ini penulis menggunakan metode yang cukup singkat pada algoritma jean meeus ini, metode tersebut adalah equation of time versi jean meeus. Implementasi berada pada fitur alarm yang ada pada sistem aplikasi. Berikut menggambarkan struktur alur metode equation of time versi jean meeus:

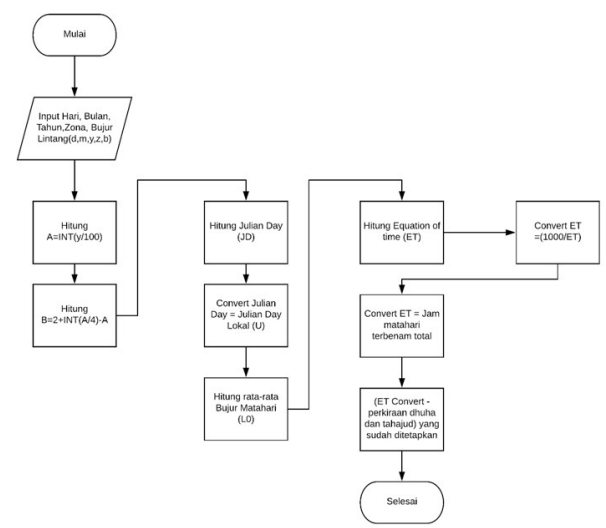

Gambar 9. Metode Equation of time versi jean meeus

Pada metode equation of time versi jean meeus terdapat angka dasar yang muncul tanpa penjelasan. Pada flowchart diatas dapat dijelaskan sebagai berikut:

a) Pertama menentukan koordinat lintang daerah (b).

b) Menentukan zona waktu daerah (z).

c) Menentukan hari, bulan dan tahun perhitungan.

d) Menghitung julian day (JD) dengan syarat menghitung A dan B terlebih dahulu.

e) $\mathrm{A}=I N T \frac{T A H U N}{100}$.

f) $\mathrm{B}=2+I N T \frac{A}{4}-A$.

g) Mengconvert Julian Day (JD) menjadi Julian Day Lokal (U).

h) $\mathrm{JD}=1720994,5+\operatorname{INT}(365,25 \times T A H U N)+I N T(30,6001(B U L A N+1))+B+H A R I$

i) $\mathrm{U}=\frac{J D-2451545}{36525}$

j) Menghitung rata-rata bujur matahari (L0).

k) $280,46607+36000,7698 \times U$ 
1) Menghitung equation of time (ET).

$1000 \times \mathrm{xET}=-(1789+237 \times U) \times \operatorname{SIN}(L 0)-(7146-62 \times U) \times \operatorname{COS}(L 0)-(29+5 \times U) \times$

$\operatorname{COS}(2 \times L 0)+(74+10 \times U) \times \operatorname{SIN}(3 \times L 0)+(320-4 \times U) \times \operatorname{COS}(3 \times L 0)-212 \times \operatorname{SIN}(4 \times$

L0)

$$
\mathrm{ET}=\frac{1000}{1000 \times E T}
$$

m) Mengconvert equation of time menjadi jam terbenam matahari total

$$
\frac{12+Z-B}{15}-\frac{E T}{60}
$$

n) Mengurangi jam terbenam matahari dengan jam dhuha dan tahajud yang telah ditetapkan dari matahari terbenam total.

TOTAL - dhuha $=$ alarm dhuha.

TOTAL - tahajud $=$ alarm tahajud.

\section{B. Implementasi Basis Data}

Implementasi basis data diambil berdasarkan perancangan basis data yang dibuat sebelumnya, secara fisik, implementasi basis data diimplementasikan menggunakan perangkat lunak MySQL server 5.1.30, tabel- tabel berikut menggambarkan struktur tabel yang diimplementasikan pada basis data.

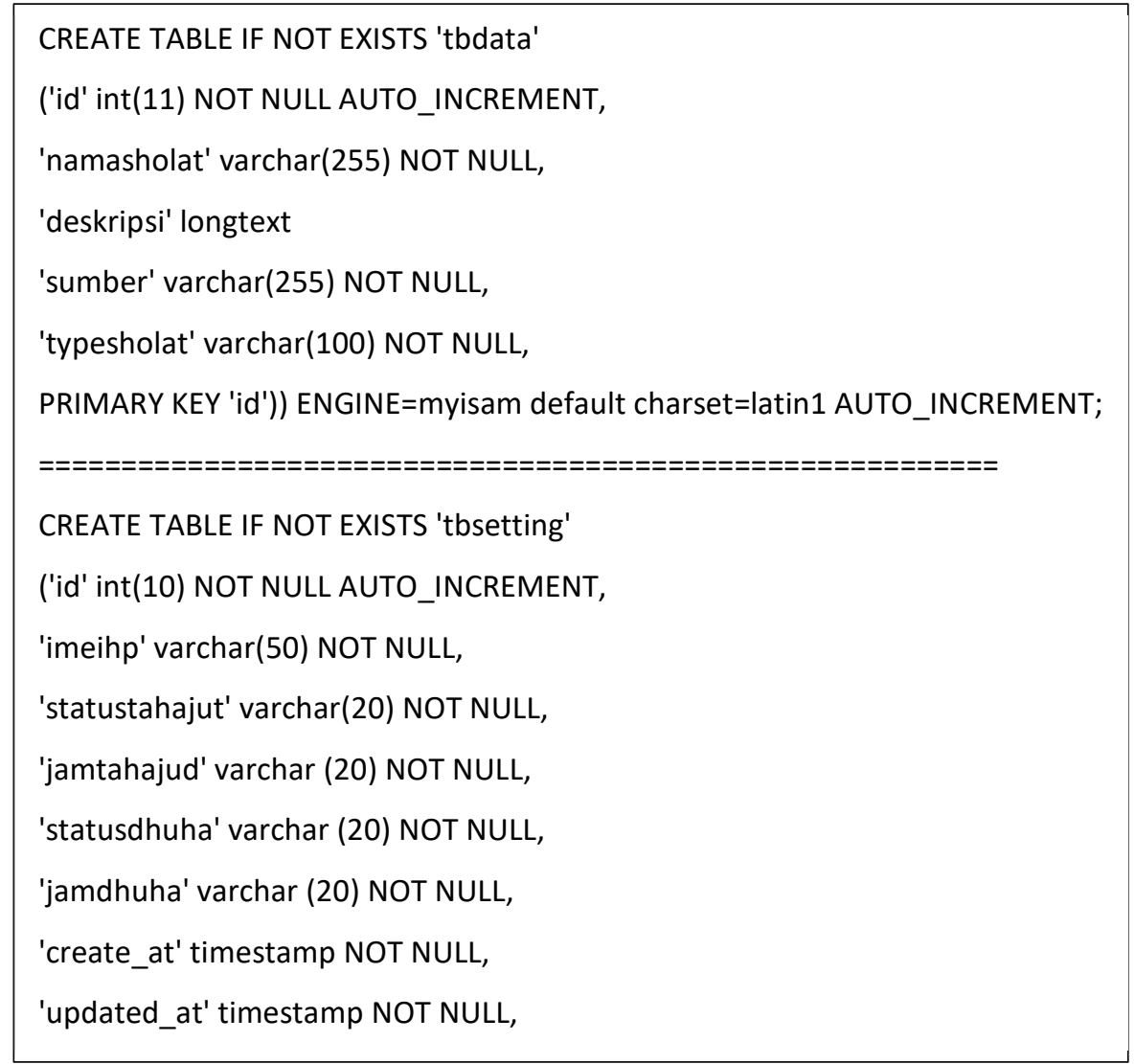

\section{PENGUJIAN}

Pengujian merupakan bagian penting dalam siklus pembuatan atau pengembangan perangkat lunak. Pengujian dilakukan untuk menjamin kualitas dan juga mengetahui kelemahan dari perangkat lunak. Tujuan dari pengujian perangkat lunak ini adalah untuk menjamin bahwa perangkat lunak yang dibangun memiliki kualitas dan dapat diandalkan. Pengujian perangkat lunak ini menggunakan metode pengujian black box. Pengujian black box digunakan untuk menguji fungsi-fungsi khusus dari aplikasi perangkat lunak yang dirancang. 


\section{Pengujian metode equation of time Algoritma Jean Meeus}

Pada tahap pengujian algoritma ini dilaksanakan implementasi perhitungan waktu shalat sunnah dhuha dan tahajud menurut metode equation of time versi algoritma jean meeus yang ditulis oleh penulis. Adapun perhitungan dari algoritma meeus itu sendiri akan dijabarkan dalam bentuk contoh kasus sebagai berikut supaya didapat pemahaman yang tepat:

Menentukan waktu shalat sunnah pada tanggal 11 Mei 2018 di Jakarta dengan Zona waktu UTC +7. Langkah langkah:

a) Tentukan zona waktu daerah tersebut $(\mathrm{Z})=7$

b) Julian day untuk 11 Mei 2018 pukul 12.00 UT. Dari tanggal tersebut diperoleh D=11, M=5, dan Y $=2018$. Dengan perhitungan:

- $\mathrm{A}=I N T \frac{Y}{100}$

- $\mathrm{A}=I N T \frac{2018}{100}$

- $\mathrm{A}=20$

- $\mathrm{B}=2+\operatorname{INT}\left(\frac{A}{4}\right)-A$

- $\mathrm{B}=2+\operatorname{INT}\left(\frac{20}{4}\right)-A$

- $\mathrm{B}=-13$

c) $\mathrm{JD}=1720994.5+\operatorname{INT}(365.25 \times Y)+\operatorname{INT}(30.6001 \times(M+1))+B+D$

$\mathrm{JD}=1720994.5+\operatorname{INT}(365.25 \times 2018)+\operatorname{INT}(30.6001 \times(5+1))+(-13)+11$

$\mathrm{JD}=2458251,5$

d) Convert menjadi JD local

$\mathrm{U}=\frac{(J D-2451545)}{36525}$

$\mathrm{U}=\frac{(2458251.5-2451545)}{36525}$

$\mathrm{U}=0,183613963$

e) Equation of time (ET), untuk dapat menghitung ET, maka Pertama kali yang harus dihitung adalah bujur rata - rata matahari (L0) dengan rumus:

$\mathrm{L} 0=280.46607+36000,7698 \times U$

$\mathrm{L} 0=280.46607+36000,7698 \times 0.183613963$

$\mathrm{L} 0=6890,710085$

f) Selanjutnya, Equation of time (ET) dapat dihitung sebagai berikut: $1000 \times E T=-(1789+237 \times U) \times \operatorname{SIN}(L 0)-(7146-62 \times U) \times \operatorname{COS}(L 0)-(29+5 \times U) \times$ $\operatorname{COS}(2 \times L 0)+(74+10+U) \times \operatorname{SIN}(3 \times L 0)+(320-4 \times U) \times \operatorname{COS}(3 \times L 0)-212 \times \operatorname{SIN}(4 \times L 0)$ $1000 \times E T=-(1789+237 \times 0.183613963) \times \operatorname{SIN}(6890.710085)-(7146-62 \times$ $0.183613963) \times \operatorname{COS}(6890.710085)-(29+5 \times 0.183613963) \times \operatorname{COS}(2 \times 6890.710085)+(74+$ $10+0.183613963) \times \operatorname{SIN}(3 \times 6890.710085)+(320-4 \times 0.183613963) \times \operatorname{COS}(3 \times$ $6890.710085)-212 \times \operatorname{SIN}(4 \times 6890.710085)$

$1000 \times E T=4866,217567$

g) Selanjutnya, dari rumus tersebut masih harus berpindah ruas dengan cara:

$$
\begin{aligned}
& \text { ET }=\frac{1000 \times E T}{1000} \\
& \text { ET }=\frac{4866.217567}{1000} \\
& \text { ET }=4.866217567
\end{aligned}
$$

h) Dari hasil ET untuk menentukan waktu pada zona waktu $=7$ digunakan rumus:

Transit $=\frac{12+Z-B}{15}-\frac{E T}{60}$

Transit $=\frac{12+7-(-13)}{15}-\frac{4.866 .217567}{60}$

Transit $=19.78556304$

i) Hasil ini kemudian dikonfersi ke bentuk jam : menit

Jam $=19$

Menit $=\frac{78556304}{1} \times 60$

Menit $=47$ 
j) Kemudian dikurangi jam pengurangan yang telah diberikan dan disepakati dalam model RAD untuk menentukan jam yang diberikan cara yang dipakai adalah dengan menghitung terlebih dahulu penerapan equation of time versi algoritma jean meeus setelah narasumber mendapatkan waktu terbenam narasumber memberikan hasil:

Untuk Dhuha dari total waktu transit diberikan 10.30

Untuk Tahajud dari total waktu transit diberikan 17.30

waktu terbaik dhuha $=19.47-10.30$

waktu terbaik dhuha $=09.17$

waktu terbaik tahajud $=19.47-17.30$

waktu terbaik tahajud $=02.17$

\section{KESIMPULAN DAN SARAN}

\section{A. Kesimpulan}

Setelah menyelesaikan serangkaian tahapan dalam merancang dan membangun aplikasi shalat sunnah tahajud dan dhuha dengan menggunakan metode perhitungan equation of time versi algoritma jean meeus pada sistem operasi android yang dimulai dari studi literatur hingga pada tahapan pengujian, maka dapat diambil kesimpulan diantaranya adalah sebagai berikut:

a) Aplikasi yang dibangun sudah dapat berjalan pada perangkat android dan dapat mengakses tampilan serta dapat memberikan alarm untuk melakukan shalat sunnah tahajud dan shalat sunnah dhuha.

b) Berbagai software (berbagai versi OS android) yang berbeda, dapat menjalankan semua fitur aplikasi dengan baik.

c) Tujuan dalam membuat aplikasi ini agar membantu masyarakat yang ingin mengetahui informasi - informasi mengenai shalat sunnah dan mengetahui waktu shalat sunnah tahajud dan dhuha terbaik dapat dilakukan.

d) Perhitungan equation of time versi algoritma jean meeus dapat diterapkan pada aplikasi ini.

e) Aplikasi ini memiliki database untuk meletakan detail shalat sunnah lain.

\section{B. Saran}

Aplikasi shalat sunnah tahajud dan shalat sunnah dhuha dengan menggunakan metode perhitungan equation of time versi algoritma jean meeus yang dibangun merupakan pengembangan pertama pada kampus UPN "veteran" Jakarta pada platform android. Oleh sebab itu perlu dilakukan pengembangan - pengembangan ke arah yang lebih baik guna memenuhi kebutuhan pengguna yang semakin bertambah. Adapun saran - saran terhadap pengembangan aplikasi ini ke depan sebagai berikut :

a) Pada pengembangan aplikasi selanjutnya diharapkan dapat dioperasikan tidak hanya di smartphone android saja, melainkan juga bisa dioperasikan pada platform yang lain seperti IOS, windows Phone, blackberry maupun platform lama karena user Indonesia masih banyak yang menggunakan Operation System tersebut.

b) Pada pengembangan aplikasi selanjutnya diharapkan dapat menambahkan fitur - fitur lain seperti fitur shalat 5 waktu, jarak masjid terdekat, forum komunikasi islami dan sebagainya supaya dapat lebih mempermudah masyarakat muslim Indonesia dalam mengerjakan kegiatan keagamaan.

c) Pada pengembangan aplikasi selanjutnya diharapkan perhitungan metode equation of time versi algoritma jean meeus menggunakan kordinat lintang daerah dan zona waktu otomatis.

d) Pada pengembangan aplikasi selanjutnya diharapkan dapat menggunakan multi bahasa yang akan memberikan manfaat dan target user yang lebih luas di bandingkan menggunakan satu bahasa.

\section{DAFTAR PUSTAKA}

[1.] Anugraha, Rinto. 2012. Mekanika Benda Langit. Yogyakarta: Universitas Gajah Mada.

[2.] Arifin, Zainul. 2012. Ilmu Falak (Cara Menghitung Dan Menentukan Arah Kiblat Rashdul Kilat, Awal Waktu Shalat penanggalan Kalender Dan Awal Bulan Qamariah). Yogyakarta: Lukita. 
[3.] Dede Muhammad Isnaeni \& Fitri Mintarsih, Feri Fahrianto. 2015. Implementasi Algoritma Meeus Dalam Penentuan Waktu Shalat Dan Pencarian Masjid Terdekat. Universitas Islam Negeri Syarif Hidayatullah. Jakarta.

[4.] Espenak, Fred. 2009. Solar Eclipse Predictions with Vsop87and Elp2000/82. https://eclipse.gsfc.nasa.gov/SEpath/ve82-predictions.html (diakses 13 Mei 2018).

[5.] Kadir, abdul. 2014. Pemprograman java untuk pemula. Yogyakarta: mediakom.

[6.] Kasman. 2015. Trik Kolaborasi Android dengan PHP \& MySQL. Yogyakarta: Lokomedia.

[7.] Maulana, Asep. 2017. Panduan Lengkap Salat Fardu \& Sunah. Jakarta: Gramedia.

[8.] Meeus, Jean. 1991. Astronomical Algorithms / Jean Meeus. Virginia: Willmann-Bell, inc

[9.] Muhtadi, Bantan. 2013. Penentuan Waktu Shalat. Jakarta: Departemen Agama.

[10.] Sabiq, Sayyid. 2017. Fiqih Sunnah Jilid 1. Jakarta: Pustaka Abdi Bangsa.

[11.] Safaat, Nazruddin. 2012. Pemograman Aplikasi Mobile Smartphone dan Tablet PC Berbasis Android. Bandung: Informatika.

[12.] Saleh, Zamzami \& Endra Kusnawan. 2016. Salat Sunah Menurut Empat Imam Mazhab. Jakarta: Gramedia.

[13.] Syaikh, Ahmad. 2010. Program Deklinasi dan Equation of Time. Semarang: www.aliboron.wordpress.com (diakses 13 Mei 2018).

[14.] Supardi, Yuniar. 2017. Koleksi Program Tugas Akhir dan Skripsi dengan Android. Jakarta: Gramedia.

[15.] Yudhanto, Yudha \& Ardhi Wijayanto. 2017. Mudah Membuat dan Berbisnis Aplikasi Android dengan Android Studio. Jakarta: Gramedia. 